\title{
Conservation status of endemic Galliformes on Hainan Island, China
}

GAO YU-REN

\section{Summary}

The Hainan Hill-partridge Arborophila ardens is endemic to the island of Hainan, which lies off the south coast of China. Distinct subspecies of the Silver Pheasant Lophura nyethemera whiteheadi and Grey Peacock-pheasant Polyplectron bicalcaratum katsumatae are also endemic to the island. All three taxa are considered endangered and are very poorly known in the wild. Surveys of remaining patches of forest were undertaken between 1987 and 1994 during which local people were interviewed and some forest areas were visited. The hill-partridge was confirmed from three blocks of forest and reported from a further four. The Silver Pheasant was found in six areas of forest and probably occurs in all remaining patches of well-developed secondary and primary forest. The Grey Peacock-pheasant was recorded in five forests and reported from a further four. The hill-partridge was more restricted in its habitat use than the other two species, the latter using well-developed secondary forest in addition to primary forests. Provisional density estimates made at Ba Wang Ling National Nature Reserve were 6-8 Hainan Hill-partridges $/ \mathrm{km}^{2}, 7.5$ Silver Pheasants $/ \mathrm{km}^{2}$ and 3.75 Grey Peacock-pheasants $/ \mathrm{km}^{2}$.

\section{Introduction}

Hainan Island lies off the south coast of China and contains three endemic Galliformes taxa; the Hainan Hill-partridge Arborophila ardens and the Hainan subspecies of the Grey Peacock-pheasant Polyplectron bicalcaratum katsumatae and Silver Pheasant Lophura nyethemera whiteheadi. Of the two pheasant subspecies, the Grey Peacock-pheasant in particular is quite distinct from other subspecies. All three taxa inhabit forest that is now very much reduced from its original extent on the island. Since 1994 logging of primary forest has been banned on Hainan, but secondary forest, in which the two pheasants have been recorded may still be cut.

Information on the three Galliformes is limited. There is no reliable information from the wild on the Hainan Hill-partridge and only morphological data exist (see Morioka 1975, Cheng et al. 1978, Gao 1991a). The Grey Peacockpheasant is considered secretive and rarely seen (Delacour 1977) and its biology on Hainan is almost unknown (Cheng et al. 1978, Gao 1991b, Gao and Yang 1991). The Silver Pheasant is also poorly known on Hainan with only broad distribution data, some collection localities and morphological data available (Gao and Yu 1995, Guangdong Institute of Entomology and Zhongshan University 1983). 
In China, all three species are protected. The hill-partridge and the peacockpheasant are both First Class Protected Species which cannot be hunted. Trapping for other purposes, such as scientific research, can only be carried out with the approval of the central Forest Ministry. The Silver Pheasant is a Second Class Protected Species and also cannot be hunted. Trapping of this species for other purposes requires approval from the provincial Forest Department.

A recent assessment of the status of all Phasianidae considered that all three taxa were endangered and were amongst the highest priorities for international Galliformes conservation action (McGowan et al. 1995, McGowan and Garson 1995). In particular, appropriate information upon which to base future management recommendations should be collected. This includes a good knowledge of the distribution of all three species on Hainan, their habitat use and current threats.

Here I report on the results on island-wide surveys and of observations made in Ba Wang Ling National Nature Reserve.

\section{Methods}

Interview surveys of the island

Surveys were conducted by public transport in 1987, 1988 and 1994, when all known habitat that might support these species was visited. This included all forest areas, which were identified with the help of the Forest Department in each county on the island. During surveys local people were asked about the presence of the three Galliformes in the area. Initially birds were described by the local people, and later photographs were shown. In some places dead birds were found in local markets whereas in other areas feathers from hunted birds were sent to me.

When birds were reported from a forest area, the forest was visited and a general description of the habitat made. The extent of each forest type was taken from statistics held by the Hainan Forest Department.

\section{Preliminary population density estimates}

More intensive observations were made in the core area $\left(19^{\circ} 05^{\prime} 39.2^{\prime \prime} \mathrm{N}, 109^{\circ}\right.$ $11^{\prime} 49.6^{\prime \prime} \mathrm{E}$ ) of the 4,000-ha Ba Wang Ling National Nature Reserve. This nationallevel protected area was chosen because it still holds primary tropical forest and is less disturbed by humans than most of the island because of inaccessibility. It is also home to the only group of the subspecies of Black Gibbon that is endemic to Hainan, Hylobates concolor hainanus.

The reserve is hilly and is covered with mountain rainforest, ravine rainforest and mountain evergreen broadleaf forest between 400 and $1700 \mathrm{~m}$ above mean sea level. The study site occupied the core area which comprises $1.6 \mathrm{~km}^{2}$ at about $1,160 \mathrm{~m}$ altitude.

In order to allow more frequent observations of these birds and make preliminary estimates of the population density of each species, we established fixed bait points which have been maintained since 1986. At any one time there were 


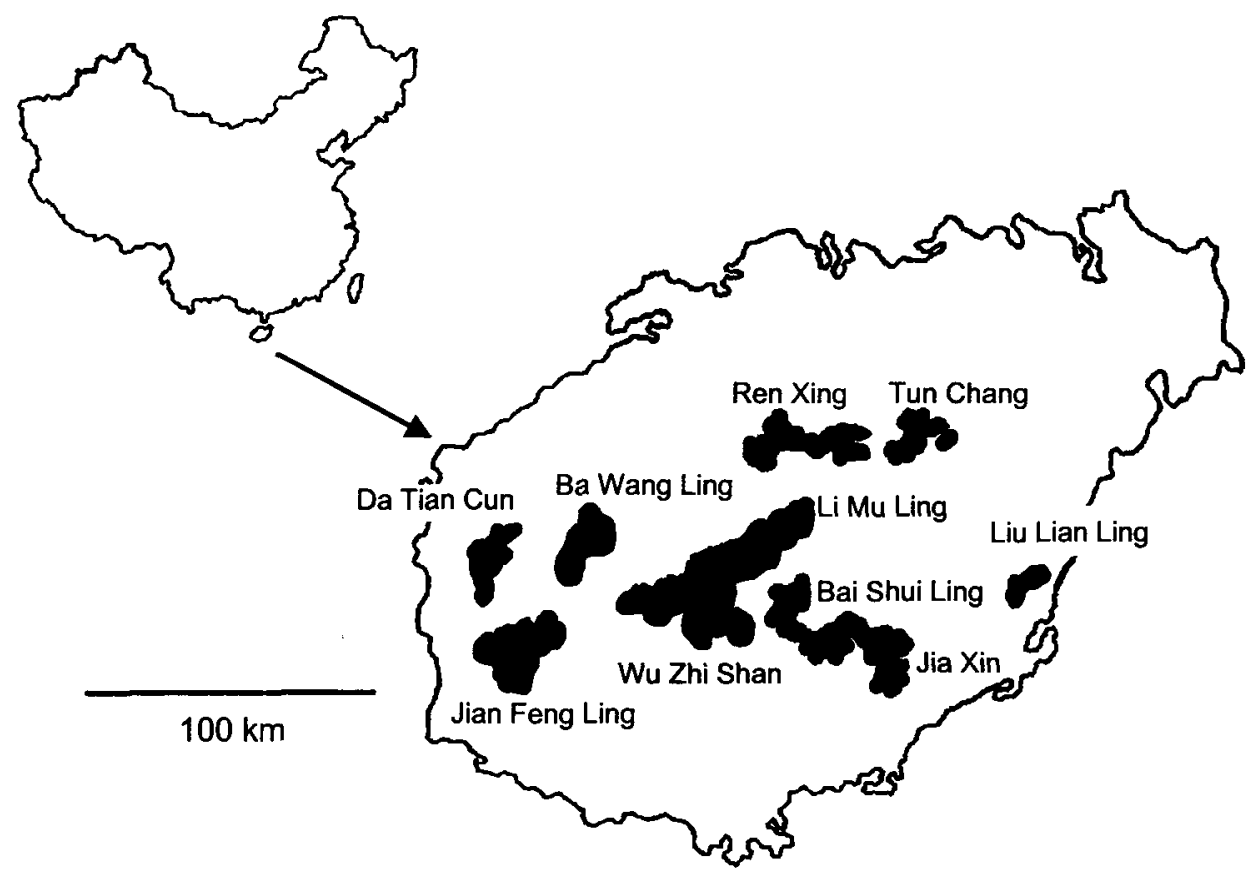

Figure 4. Map of Hainan Island, China showing main blocks of forest mentioned in the text.

between 3 and 10 fixed points. Some points were abandoned when birds no longer came to feed. All points, were baited with rice grains.

Long-term observations of these points allowed some individuals to be identified, such as Silver Pheasants with characteristic feathering during the moult. It was believed that other individuals could be identified through their regular feeding routine as they arrived at a particular bait spot at the same time each day. Over a long period of time, we believed that this allowed us to determine the number of birds in the core area. The population density was then calculated by dividing this number by the size of the core area $\left(1.6 \mathrm{~km}^{2}\right)$ to give the number of birds per $\mathrm{km}^{2}$. In October 1993, the hill-partridge and peacock-pheasant population estimates were based on counts made in the core area plus an additional $0.64 \mathrm{~km}^{2}$ of adjacent habitat, thus giving a total of $2.14 \mathrm{~km}^{2}$. Playback was used to elicit responses from hill-partridges over $1 \mathrm{~km}^{2}$ during March 1997.

\section{Results}

\section{Survey of the island}

The Hainan hill-partridge was confirmed at three places in the mountain forests in the central part of Hainan Island: Ba Wang Ling, Tun Chan and Ren Xing (Figure 1). In addition, there are apparently reliable local reports from Bai Shui Ling, Wu Zhi Shan, Li Mu Ling, Jian Feng Ling. All of these areas lie between $64 \mathrm{om}$ and 1,28om above sea level. Hill-partridges appear to be restricted to prim- 
ary mountain rain forests: mountain evergreen forests (including broadleaf or mixed coniferous and broadleaved forests), ravine rain forests, and some logged but well-recovered monsoon evergreen forests.

The Hainan Silver Pheasant was found at Ba Wang Ling, Jian Feng Ling, Li $\mathrm{Mu}$ Ling, Wu Zhi Shan, Ba Shui Ling and Jia Xin. The species is reported from most areas on Hainan where there is still suitable forest. Together with the Grey Peacock-pheasant it inhabits a broader range of habitat types than the hillpartridge, being found in well-developed secondary forest as well as undisturbed tropical forests, including ravine rainforest, mountain rainforest, mountain evergreen broadleaf forest and mixed coniferous and broadleaved forest. The two species occupy a similar elevation range to the hill-partridge, from $600 \mathrm{~m}$ to 1200 $\mathrm{m}$. The Silver Pheasant is occasionally found down to $200 \mathrm{~m}$ elevation.

The Hainan Grey Peacock-pheasant was confirmed at Ba Wang Ling, Li Mu Ling, Ren Xing and Tun Chang in the centre of the island, and also in Bai Shui Ling to the south. Locals report the species from Da Tian Cun in the Da Tian Eldi Deer Reserve, Jian Feng Ling, Liu Lian Ling and Jia Xin. The peacock-pheasant is found in the same range of habitats and elevations as the Silver Pheasant. In Da Tian Cun, locals report it as low as $100 \mathrm{~m}$ elevation.

\section{Provisional population density estimates}

In the core area at Ba Wang Ling, the population density of Hainan Hill-partridge was 6.54 birds $/ \mathrm{km}^{2}$ ( 14 birds in $2.14 \mathrm{~km}^{2}$ ) in October 1993 and $6-8 \mathrm{birds} / \mathrm{km}^{2}$ (3 or 4 males, assumed to represent pairs, responding to playback over $1 \mathrm{~km}^{2}$ ) in March 1997.

The population density of the Grey Peacock-pheasant was provisionally estimated at $3.75 / \mathrm{km}^{2}\left(6\right.$ birds in $1.6 \mathrm{~km}^{2}$ ) in October 1992 and $3.74 / \mathrm{km}^{2}$ (8 birds in $2.14 \mathrm{~km}^{2}$ ) in October 1993. The provisional Silver Pheasant population density estimate was 7.5 birds $/ \mathrm{km}^{2}$ ( 12 birds in $1.6 \mathrm{~km}^{2}$ ) in December 1992.

\section{Extent of remaining habitat}

Calculations using statistics held by the Forest Department and the results from our surveys suggest that all three taxa now occupy very small ranges. The Hainan Hill-partridge is probably restricted to almost intact forest that covers only $660 \mathrm{~km}^{2}$, of which about $410 \mathrm{~km}^{2}$ is in reserves and $240 \mathrm{~km}^{2}$ lies outside. The Grey Peacock-pheasant and the Silver Pheasant appear slightly less restricted in their habitat use, and the forest types in which they were found extend over $740 \mathrm{~km}^{2}$, of which $440 \mathrm{~km}^{2}$ is in reserves and $300 \mathrm{~km}^{2}$ is outside.

Extrapolating the preliminary estimates of population size in the core area at Ba Wang Ling National Nature Reserve to the extent of the remaining forest gives the following tentative estimates for the three taxa on Hainan: hillpartridge, 3,900-5,200; Silver Pheasant, 5,550; and the peacock-pheasant, 2,775.

\section{Discussion}

This study has provided baseline information on the conservation status of the three endemic taxa of Galliformes on Hainan Island. The Hainan Hill-partridge 
appears to have the most restricted habitat requirements and the world population of this species may number fewer than 5000 individuals. The two endemic pheasant subspecies occupy a slightly wider range of habitats and in particular can tolerate limited habitat alteration as they were found in well developed secondary forest. Both, however, are also likely to have very small populations.

All three taxa have suffered from habitat loss as their forest habitat has been felled. The hill-partridge is especially vulnerable to this pressure as it does not appear to occur in any secondary habitat, except very well-developed forest with deep litter. Hunting for food using both traps and guns has also been a problem for these species and is still a cause for concern despite their protected status. Addressing these issues is mainly a legal matter, although research into ways in which forestry practices might be less harmful to the hill-partridge and pheasants may provide vital information. The information presented here can be used as the basis for programmes of awareness on the plight of these Galliformes and other endemic forest wildlife on Hainan.

Fortunately, the government of Hainan Island prohibited logging of oldgrowth tropical rainforest after I January 1994. However, the forest is already broken up into many small patches. In the long term, this fragmentation of the forest into small and widely separated patches is likely to result in all three species being comprised of several small and isolated populations of unknown viability.

There are 78 nature reserves on Hainan; five are National Nature Reserves, and most of the remainder are provincial-level Nature Reserves. There are a few areas that are protected at county level. Many of these areas are very small and may be too small to conserve viable populations in the long term. Therefore, there is a need to identify the most important areas and determine whether any might be joined together, as proposed for south-west Hainan by Mackinnon et al. (1996). Research into both forestry practices and the distribution of protected areas might be necessary before we can be sure that sufficient suitable habitat will remain for these three endemic Galliformes and many other endemic taxa.

\section{Acknowledgements}

The research was funded by the National Natural Science Foundation of China. I am also very grateful to the Head of the Wildlife Station of the Hainan Province Forest Department and the staff at Ba Wang Ling National Nature Reserve, especially Yu De-gun, for all their help since 1986. The World Pheasant Association funded my attendance at the International Galliformes Symposium in Malaysia where this work was presented, and I thank them for their support. I especially thank John Carroll and Philip McGowan (both of whom made helpful comments on the manuscript) and Peter Garson for all their assistance.

\section{References}

Cheng Tso-hsin, Tan Yao-kuang, Lu Tai-chun, Tang Chan-zhu, Bao Guijun and Li Fu-lai (1978) [Fauna Sinica, Series Vertebrata. Aves, 4. Galliformes. Beijing: Science Press] (in Chinese). 
Delacour, J. (1977) The pheasants of the world, second edition. Hindhead, U.K.: Spur Publications.

Gao Yu-ren (1991a) [The Hainan Hill Partridge. Pp. 149-152 in Lu Tai-chun, editor-inchief. The rare and endangered gamebirds in China. Fuzhou: Fujan Science and Technology Press] (in Chinese).

Gao Yu-ren (1991b) Present situation of the Grey Peacock-pheasant on Hainan Island. World Pheasant Assoc. News 38: 8-10.

Gao Yu-ren and Yang Lan (1991) [The Grey Peacock-pheasant. Pp. 390-394 in Lu Tai-chun, editor-in-chief. The rare and endangered gamebirds in China. Fuzhou: Fujan Science and Technology Press (In Chinese).

Gao Yu-ren and Yu De-qun (1995) [The ecology and situation of the Hainan subspecies of Silver Pheasant. Zool. Res. 16: 353-358] (in Chinese with English summary).

Guangdong Institute of Entomology, Zoology Division and Zhongshan University, Biology Department (1983) [Birds and mammals of Hainan Island. Beijing: Science Press] (in Chinese).

Mackinnon, J., Meng Sha, Cheung, C., Carey, G. Zhu Xiang and Melville, D. (1996) A biodiversity review of China. Hong Kong: WWF International.

McGowan, P. J. K. and Garson, P. J. (1995) Pheasants: status survey and conservation action plan 1995-1999. Gland, Switzerland: IUCN.

McGowan, P. J. K., Dowell, S. D., Carroll, J. P. and Aebischer, N. J. (1995) Partridges, quails, francolins, snowcocks and guineafowl: status survey and conservation action plan 1995-1999. Gland, Switzerland: IUCN.

Morioka, H. (1957) The Hainan Tree-partridge Arborophila ardens. Ibis 99: 344-346.

GAO YU-REN

South China Institute of Endangered Animals, Guangzhou 610260, China. 